\title{
Dona Henriqueta: o leitor e os contos de Artur Azevedo
}

Emerson Tin

\section{Introdução}

Célebre comediógrafo e crítico atuante em diversos periódicos da então Capital Federal, Artur Azevedo também tinha a sua face de conteur. Tanto nas páginas reunidas pelo próprio escritor em livro quanto no habitual conto publicado em jornais como O País, a verve do autor d'A Capital Federal era apreciada por seus inúmeros leitores. Sua importância como contista na passagem do século XIX ao XX foi tanta que levou Lúcia Miguel-Pereira a observar que "se não existisse Machado de Assis, poderíamos dizer que no conto, com Domício da Gama e Artur Azevedo, estava o melhor da nossa produção" (MIGUEL-PEREIRA, 1973, p.242), traçando-lhe o perfil em seguida:

\begin{abstract}
Observador isento dos hábitos da capital, narrou com rara graça e simplicidade os seus casos e anedotas. [...] tudo o que se passava nas ruas ou nas casas lhe forneceu assunto para historietas cujos protagonistas são sempre marcadamente cariocas. A pequena comédia quotidiana foi por ele fixada em ilustrativos flagrantes. E o êxito alcançado por seus livros thes demonstra a facilidade e amenidade da leitura, a graciosa fluência do estilo. (MIGUEL-PEREIRA, 1973, p.272)
\end{abstract}

É esse caráter cômico, que nos leva do riso discreto à gargalhada solta, talvez o traço mais característico da maioria dos contos de Artur Azevedo. Muitos de seus contos são perfeitos exemplos de construção narrativa, seja pela economia, seja pelo sucesso dos efeitos pretendidos. Muitas vezes Artur Azevedo mantém o leitor em suspenso, aguardando o desenlace da trama, que coincide, quase sempre, com a conclusão da narrativa.

Uma dessas estratégias narrativas é justamente a chamada narrativa "de encaixe" ou enquadrada, ou seja, quando o narrador inclui uma outra história dentro da história que vinha sendo narrada - na maior parte das vezes, narrada oralmente, em diálogo estabelecido entre o narrador e uma outra personagem. Esse recurso combina perfeitamente com a oralidade marcante dos contos de Artur Azevedo, o que faz lembrar a proximidade entre o conto literário e o conto oral, na síntese de Horacio Quiroga, lembrada por Nádia Battella Gotlib: "O conto literário consta dos mesmos elementos que o conto oral e é, como este, o relato de uma história bastante interessante e suficientemente breve para que absorva toda a nossa atenção." (GOTLIB, 1991, p.76)

As narrativas "de encaixe" de Artur Azevedo, contudo, não aparecem apenas como recurso para absorver a atenção do leitor ou reforçar a verossimilhança da 
história mas também como um reflexo - talvez uma reflexão? - sobre a própria arte do conto e sua comunicação com o público leitor. Nessas narrativas enquadradas, o narrador - Artur Azevedo lui-même - aparece como paciente ouvinte de leitores seus, empenhados em lhe apresentar "magníficos assuntos para este gênero de literatura amena”, nas palavras do conto "O jaó”.

\section{O leitor, ora o leitor...}

Talvez não seja absurdo imaginar o efeito da recepção dos contos de Artur Azevedo pelos leitores da época no próprio processo de escrita do autor maranhense. Raimundo Magalhães Júnior relata como os portugueses moradores no Rio de Janeiro teriam se irritado com seu conto intitulado "Incruento"1:

Outra vez se irritaram os portugueses quando Artur publicou n'O País o conto apimentado a que deu o título de "Incruento". E que é mais uma anedota do que um conto. Um comerciante quer que um dos seus caixeiros case com a filha.

- Muito bem, - responde o caixeiro agradecido.

- Mas há uma coisa: é que a menina não é mais donzela...

- Ora, patrão, replica o caixeiro - Nem que fosse!

Tal conto foi interpretado como "uma ofensa a uma colônia laboriosa e honesta". Choveram cartas indignadas, de portugueses, à redação. E Artur se viu obrigado a responder. Onde, na historieta, se declarava que o caixeiro era português? Não aludia o autor à nacionalidade do personagem, que tanto podia ser português como brasileiro. Mas a colônia lusa dera para achar que em tudo quanto saía da pena de Artur havia alusões ferinas aos portugueses. Ostensivas, umas; dissimuladas, outras... (MAGALHÃES JÚNIOR, 1953, pp.185-6)

Assim, talvez não faltassem críticas ao contista... Mas também não lhe faltavam leitores habituais. É o que, de certo modo, pode-se concluir da insistente personagem de "Assunto para um conto", exemplo extremo dos indivíduos que, constantemente, abordariam o autor para lhe oferecer assuntos:

Como sou um contador de histórias, e tenho que inventar um conto por semana, sendo, aliás, menos infeliz que Scherazada, porque o público é um sultão Shariar menos exigente e menos sanguinário que o das Mile Urna Noites, sou constantemente abordado por indivíduos que me oferecem assuntos, e aos quais não dou atenção, porque eles em geral não têm uma idéia aproveitável.

Entre esses indivíduos há um funcionário aposentado, que na sua roda é tido por espirituoso, o qual, todas as vezes que me encontra, obriga-me a parar, diz-me, invariavelmente, que estou ficando muito preguiçoso, e, com um ar de proteção, o ar de um Mecenas desejoso de prestar um serviço que aliás não the foi pedido, conclui, também invariavelmente:

- Deixe estar, que tenho um magnífico assunto para você escrever um conto! Qualquer dia destes, quando eu estiver de maré, lá lh'o mandarei. (AZEVEDO, 1974, p. 117)

Essa idéia se reforça com a leitura da cena inicial do conto “O jaó”, um exemplo de narrativa enquadrada, recolhido postumamente no livro Contos cariocas, de 1928: 
Numa noite em que estávamos quatro ou cinco amigos reunidos em casa do Novais, vieram à baila os meus contos e não houve na assistência quem se não gabasse de saber casos que forneceriam magníficos assuntos para este gênero de literatura amena.

- Pode ser - disse eu - mas devo confessar-lhes que até hoje não pude aproveitar para os meus trabalhos um único assunto oferecido nessas condições. Os contos inventaramse, o que não quer dizer que não sejam também o produto do que se vê e observa na vida real, ou o renovamento de qualquer anedota que corra mundo desde tempos imemoriais.

- Ora! Eu sei a história de um jaó, que te poderia servir, disse-me o Novais, e vou contála enquanto minha mulher apronta o chá!

- Conta, que ele há de gostar - disse D. Emília, desaparecendo da sala.

- Vamos à história do jaó! - exclamei, fingindo-me entusiasmado, para dar ânimo ao

dono da casa. (AZEVEDO, [197-?], p.153)

Após a injeção de ânimo, o anfitrião inicia a história, e Artur Azevedo lhe dá a voz até o epílogo que, como uma chave de ouro, emoldura a narrativa e esclarece o título do conto:

O Novais calou-se.

- Está terminado o conto? - perguntei depois de uma pausa.

- Está; não o achas interessante?

- Não é mau, mas falta-lhe a conclusão. Que fim levou o jaó?

- Aqui o tens na tua presença, meu amigo; o jaó era eu.

- E a Mimi, esta sua criada - acrescentou D. Emília, que voltava com a bandeja do chá.

(AZEVEDO, [197-?], p.153)

Mas entre os inúmeros indivíduos que abordariam Artur Azevedo para lhe oferecer assunto para um conto, havia um que, ao que parece, era ouvido com prazer pelo escritor: tratava-se da espirituosa amiga dona Henriqueta.

\section{Dona Henriqueta ouve histórias}

Personagem secundária do conto "As asneiras do Guedes" - também recolhido entre os Contos cariocas -, dona Henriqueta figura como o contraponto do narrador em pelos menos seis narrativas de encaixe, todas elas reunidas entre os Contos efêmeros, de 1897. É naquele conto que encontramos um rápido esboço da personagem:

Eu estava num armarinho da rua do Ouvidor, onde entrava para cumprimentar a minha espirituosa amiga D. Henriqueta, que andava, como sempre, fazendo compras, enchendo-se de caixinhas e pequeninos embrulhos, adquiridos aqui e ali (AZEVEDO, 1973, pp.59-60)

O primeiro dos Contos efêmeros em que surge a espirituosa dona Henriqueta é "O númbaro". O encontro entre o narrador e a personagem se dá de forma casual:

Eu descia descuidosamente a rua do Ouvidor, quando uma voz argentina cantou aos meus ouvidos: 
- Fale com os pobres.

Voltei-me. Era a minha espirituosa amiga dona Henriqueta, que me estendeu a mão corretamente enluvada. (AZEVEDO, [1924], p.21)

Estão traçados aí os elementos fundamentais dos seis contos em que aparece dona Henriqueta: o encontro casual se dá sempre na rua (rua do Ouvidor, rua dos Ourives, praça Quinze de Novembro) ou em algum estabelecimento comercial (um armarinho, a livraria do editor Domingos de Magalhães); trava-se um diálogo entre o narrador e a personagem sobre um assunto corriqueiro e, ao sabor da conversa, chega-se ao "assunto do conto", que será encaixilhado pela cena entre o narrador e dona Henriqueta.

Mas essa conversa mantida pelo narrador e dona Henriqueta não é apenas pretexto para a narrativa nem recurso para reforço ou garantia da verossimilhança. Há mais do que isso nesse caso. Voltemos ao conto "O númbaro". Após a espirituosa amiga pedir-lhe um conto, o narrador responde negativamente, dizendo não ter "nenhum conto debaixo da língua, mas... não resisto ao prazer de acompanhá-la". Em seguida, após uma pausa, introduz novo tema na conversa:

- Sabe que estou profundamente contrariado?

- Sim?... Por quê?

- Imagine que acabo de receber uma carta anônima...

E tirei do bolso uma carta.

- ... em que me passam uma descompostura tremenda. (AZEVEDO, [1924], p.22)

A descompostura era em razão de um erro de gramática num conto: um leitor que, não querendo ser visto como um caturra gramatical, escondia-se com o véu do anonimato, mas não deixava de espicaçar o autor:

- O que me contraria, minha senhora, não é a descompostura... mas imagine que o meu agressor encontrou um erro de gramática, um erro terrível no meu último conto: escrevi um the por um $a$; cometi, por descuido, um brasileirismo em que aliás incorreram já escritores de mais autoridade. Antes de receber a carta, já eu tinha notado e mentalmente retificado o engano. Achava-me na doce persuasão de que ninguém daria por ele, quando esta maldita carta...

- Não esteja contrariado: o crime não é tamanho...

- Ah, sim... esse não foi o meu primeiro erro de gramática e provavelmente não será o último... Mas que quer, dona Henriqueta? Quem escreve para o público tem obrigação de pôr o maior cuidado no que faz... Contrariou-me ter escrito aquela asneira, e ainda mais me contrariou saber que a descobriram.

- Ora! Os erros de sintaxe jamais causaram dano aos amores. (AZEVEDO, [1924], pp.22-3)

O erro, por si, não era a causa do dissabor - até porque escritores de mais autoridade já o teriam cometido -, mas sim saber que o erro havia sido identificado pelo leitor. Daí por diante, a conversa envereda por uma breve exposição sobre o pouco dano que os erros de sintaxe e ortografia causariam aos amores, para chegar 
ao ponto da condenação dos erros de prosódia - mote do conto, em que a protagonista, Florinda, erra a pronúncia da palavra "número", falando "númbaro":

- Pois, sim, mas a prosódia...

- Ah! Isso é outra coisa! O homem instruído perdoa todas as asneiras que a mulher amada escreva, mas não suporta que ela fale mal.

- É uma desilusão.

- A esse propósito, dona Henriqueta, contar-lhe-ei uma pequena história...

- Ah, bom! Sempre tinha um conto debaixo da língua... Como se intitula?

- Pode intitular-se o Númbaro.

- O Númbaro?... que quer isso dizer?...

- Verá. Prepare o leque para as situações escabrosas. (AZEVEDO, [1924], 24)

Situações escabrosas, aliás, que, na opinião de dona Henriqueta, não faltavam aos contos de Artur Azevedo. É essa a reprimenda que lemos na abertura do conto "Incruento":

- Vamos lá! - disse a minha espirituosa amiga dona Henriqueta -, vamos lá! O senhor às vezes escreve contos que uma senhora não pode ler sem corar...

- Ora essa! Peço-lhe que me cite um só desses contos!

- A filha do patrão, por exemplo...

- Confesso-lhe, dona Henriqueta, que não me lembro absolutamente do assunto.

- Pois eu avivo-lhe a memória: trata-se de uma rapariga, filha de certo comendador abastado, que ama um rapaz sem posição nem fortuna. (AZEVEDO, [1924], p.151)

Como estratégia narrativa, para não atrapalhar o leitor que não conhecesse o conto, Azevedo faz o narrador não se lembrar do conto para que dona Henriqueta o apresente em síntese. Segue, então, o diálogo:

- Então? Que inconveniência tem esse conto?

- Até aí nenhuma; o final, porém, é terrível: o comendador convence a pequena de que deve ser esposa do seu primeiro caixeiro, e ela deixa-se convencer.

- Vai então o velho, chama de parte o caixeiro, diz-lhe que está satisfeito com os seus serviços, dá-lhe interesse na casa e propõe-lhe o casamento; é isso?

- É isso, é; o moço fica atônito diante de tão inesperadas fortunas; mas o futuro sogro...

- Previne-o de que a filha não é virgem.

- Ora vejam se isto são coisas que se escrevam!

- O primeiro caixeiro abaixa a cabeça, abre um sorriso humilde, encolhe-se e diz: Oh, patrão, ainda que fosse não fazia mal.

- O cinismo com que o senhor repete essa brejeirice, aqui, diante de uma senhora!

(AZEVEDO, [1924], pp.152-3)

Não é abusivo imaginar que o conto “A filha do patrão" - recolhido em 1894 nos Contos fora da moda - tivera grande repercussão entre os leitores, o que teria motivado Artur Azevedo a retomar-lhe a história e escrever-lhe uma continuação. Pois a narrativa enquadrada de "Incruento" é justamente a continuação daquele conto fora da moda. Mas, antes de iniciar a narrativa, o narrador defende-se da crítica de 
dona Henriqueta - e, defendendo-se dela, não se estaria defendendo de todos os críticos?

- Valha-me Deus, dona Henriqueta! Vejo que infelizmente vim encontrá-la numa terrível disposição de intolerância. Esse conto não perverte ninguém; é pura e simplesmente uma pálida pintura do que se passa em certo meio social.

- Ah! Se o senhor entende que pode descrever tudo quanto se passa na sociedade, arrisca-se a ser denunciado à justiça por ofender a moralidade pública.

- Pois saiba, dona Henriqueta, que tenho outro conto em continuação daquele.

- Sim? E como se intitula?

- Incruento.

- Que mau título!

- É um título como outro qualquer. A ação desse conto passa-se no dia seguinte ao do casamento do primeiro caixeiro com a filha do patrão.

- Conte-me isso, mas pelo amor de Deus não me faça corar...

- Oh, dona Henriqueta, pois não tem aí o seu leque?

- Vamos lá! (AZEVEDO, [1924], p.153)

Mas nem todos os contos faziam dona Henriqueta corar. Em "Aquele mulatinho!", o narrador é o cronista do cotidiano carioca, e o diálogo se dá a partir das observações sobre a estátua de Osório, colocada na praça Quinze de Novembro:

Eu contemplava, na praça Quinze de Novembro, a bela estátua de Osório, que acabava de ser inaugurada, e divertia-me a ouvir os comentários das pessoas que se achavam perto de mim, quando senti uma pequenina mão pousar delicadamente sobre o meu ombro. Voltei-me: era ela, a minha espirituosa amiga dona Henriqueta.

Depois de afogarmos a nossa velha saudade num vigoroso aperto de mão, demos um ao outro notícias nossas, escolhendo afinal para assunto da conversa o monumento que diante de nós se erguia majestoso e sereno na sua grande simplicidade artística.

Em volta um sujeito dizia que Osório devia calçar botas; outro afirmava que a cauda do cavalo estava exageradamente erguida; uma senhora achava que o general podia estar menos empinado, e todos a uma davam sentenças.

A minha espirituosa amiga, que é dotada de certo discernimento artístico e admira o bronze de Bernardelli, ria-se a bom rir de todos esses comentários.

Um indivíduo que eu não conheço, depois de contemplar o monumento por uns bons cinco minutos, voltou-se para o meu lado e disse-me:

- Está tudo muito bom; apenas quer me parecer que a estátua foi mal colocada...

- Como assim? - perguntei.

- Acho que o monumento ficaria melhor se o cavalo olhasse para a repartição dos telégrafos.

- Ora essa! Por quê?

- Não sei... é cá uma idéia... parece-me que haveria assim mais harmonia entre o monumento e a praça. (AZEVEDO, [1924], pp.173-4)

O público que palpitava em torno da estátua não seria o mesmo público que palpitava sobre os contos de Artur Azevedo? Que escrevia aos jornais? Que lhe propunha assuntos para contos? A observação desse último indivíduo sobre a estátua de Osório daria ao narrador o mote do conto: 
- Este senhor, disse eu à minha espirituosa amiga, faz-me lembrar um caso engraçado que se deu na minha terra quando se tratava de levantar ali a estátua de Gonçalves Dias.

- Se é realmente engraçado, quero ouvi-lo; acompanhe-me até o bonde. (AZEVEDO, [1924], p.174)

Era esse o desejo de dona Henriqueta: uma história que a entretivesse até o bonde... Talvez fosse esse também o desejo dos leitores de Artur Azevedo. Mas assim como o colaborador acidental de "Assunto para um conto" ou o anfitrião empenhado de "O jaó", dona Henriqueta teve seus momentos de narradora.

\section{Dona Henriqueta conta bistórias}

Em "Os charutos", é a espirituosa amiga quem conta uma história ao narrador. Encontrando-a casualmente na rua dos Ourives, o narrador acompanha-a ao dentista para poder ouvir o que tinha a dizer:

- Tenho aqui na ponta da língua uma história para os seus leitores.

$-\operatorname{Sim}$ ?

- Ah! Mas é preciso escrevê-la com muito cuidado. Foi uma amiga minha que m'a contou. Não creio que seja inédita, mas é engraçada.

- Ouçamos.

E dona Henriqueta contou-me a história que vou reproduzir. Enquanto contava, ria-se a perder [...] Vamos ao conto. Se algum dos leitores já o conhecer, tanto pior para mim. (AZEVEDO, [1924], pp.49-50)

Todas as escusas do narrador sobre a dúvida quanto ao ineditismo da narrativa se justificariam². Em nota ao volume dos Contos efêmeros, diria Artur Azevedo:

Poucos dias depois de publicado este conto no País, recebi uma carta anônima em que me acusavam de o haver copiado do livro de Victor Tissot l'Allemagne amoureuse. Mais tarde um folhetinista da Cidade do Rio afirmou aos seus leitores que os Charutos eram plagiados de um conto de Armand Silvestre. (AZEVEDO, [1924], p.243)

O que segue, então, é uma lição sobre a arte do conto de Artur Azevedo:

O fato explica-se do seguinte modo: os dois escritores franceses fizeram o mesmo que eu fiz - aproveitaram uma velha anedota anônima e contaram-na cada qual a seu modo, exercendo assim um direito permitido neste gênero de literatura. Não existe plágio, desde que o autor tenha dado uma forma original à sua narrativa.

Se arranjar um conto com uma velha anedota é plagiar, plagia o escritor que romantiza ou dramatiza qualquer fato histórico. A história não se inventa. (AZEVEDO, [1924], pp.243-4)

A forma original, para além da própria narrativa na linguagem característica de Artur Azevedo, estava na narrativa "de encaixe" em que a havia inserido. Não era 
a história sobre os "charutos" o que mais importava, porém a forma de contá-la, o seu enredo. Isso é que deveria surpreender o leitor, muito mais que os fatos narrados em si mesmos. Nesse sentido, "Os charutos" tem uma cena final, à guisa de epílogo, em que retornam o narrador e dona Henriqueta:

Dona Henriqueta, quando acabou de me contar essa história, pediu-me que a esperasse para acompanhá-la ao ponto dos bondes no largo da Carioca.

Esperei pacientemente que o Chapot Prevost the examinasse as pérolas (porque, creiam, os seus dentes são verdadeiras pérolas) e, acabado o exame, tive o prazer de levá-la até o bonde.

Já ela estava sentada quando de repente:

- Ah! E eu me esqueci completamente...

- De que?

- E note-se que não vim à cidade para outra coisa! Meu marido faz anos hoje, e não lhe levo um presente!

- Ainda há tempo.

- Qual! Já é tarde e chove tanto... Se eu pudesse arranjar alguma coisa aqui mesmo no largo da Carioca...

- Pode, por que não? Seu marido não fuma? Está ali a charutaria do Machado, que... A minha espirituosa amiga deu um muxoxo e voltou o rosto para sorrir à vontade.

O bonde partiu. (AZEVEDO, [1924], pp.54-5)

A cena final do conto, para além de arrematá-lo, está intimamente ligada à história contada por dona Henriqueta, de onde extrai sua comicidade: se, na história contada pela espirituosa amiga, a objeção de Izabelinha a que o marido fumasse na cama teria dado início ao silêncio do marido, que não conversava com ela - evidente eufemismo para a abstinência sexual imposta pelo marido à esposa antitabagista -, na vida conjugal de dona Henriqueta provavelmente as conversas com o marido deveriam ser bastante proveitosas...

Assim Artur Azevedo mostrava aos seus leitores, por meio de sua leitorasímbolo, que a arte do conto estaria menos na história que no modo de contá-la. Aliás, é esse o mote para o conto "Episódio de viagem":

Depois de esmagarmos as saudades num vigoroso aperto de mão, sentei-me ao lado de dona Henriqueta e pedi-lhe que me desse notícias da sua pessoa.

A minha espirituosa amiga fez-me a longa nomenclatura das cidades, vilas, povoações e fazendas do Estado do Rio por onde andara em estradas de ferro, a cavalo, em canoa, de trole e cadeirinha, passando aqui dois dias, quatro ali, seis acolá, sempre em movimento, viajando sempre.

- Deve ter muitos episódios interessantes para contar-me.

- Nem por isso. O senhor bem sabe que a vida da roça é de uma monotonia terrível. As paisagens assemelham-se e em toda a parte o viajante encontra as mesmas fisionomias.

- Mas é impossível que não traga ao menos uma história.

- O episódio mais engraçado da minha viagem é daqueles que o senhor não pode aproveitar.

- Por quê?

- Porque... não é coisa que se conte.

- Ora deixe-se disso! Tudo se conta; o caso é saber contar... 
- Dou-lhe um doce se for capaz de escrever que nos sucedeu em Marica, a meu marido

e a mim.

- Vejamos.

- Ora ouça.

E a minha espirituosa amiga dona Henriqueta contou-me o seguinte (AZEVEDO, [1924], pp.197-8).

A narrativa gira em torno das dificuldades encontradas pelo casal no hotel em que se hospedaram. Não havendo nenhum quarto desocupado, o hoteleiro alemão Fritz improvisou uma acomodação para o casal, mas se esqueceu "de que a natureza tem exigências indeclináveis" e "não havia nada embaixo da cama". O marido segreda a Fritz a causa de sua preocupação: "É impossível! - respondeu o alemão. Não há mais nenhum!" Mas Fritz acaba improvisando e entrega ao marido de dona Henriqueta uma garrafa grande e bojuda. Aliviado, o marido se deita, mas logo tem de atender aos pedidos da esposa, que não pode se arranjar com a garrafa, como fez o marido:

- Seu Fritz! Seu Fritz!

Veio o alemão.

- Não tenho palavras para agradecer-lhe bastante o ter-me proporcionado aquela garrafa... mas minha mulher também queria... e você compreende que...

- Tem razão, disse o hoteleiro.

E desapareceu.

Daí a pouco volveu, trazendo-nos... um funil. (AZEVEDO, [1924], p.201)

Tudo se conta: o caso é saber contar. Nesse sentido, situação semelhante havia sido narrada por Artur Azevedo no conto "Pobres liberais!" - que seria recolhido em Vida alheia, de 1929: um presidente de província que se vê obrigado a lançar mão de um jornal que lhe veiculava homenagens por não encontrar em seu quarto "o receptáculo sem o qual não poderia obedecer à natureza" (AZEVEDO, 1967, 34).

Ao que parece, porém, dona Henriqueta não poderia concordar com a máxima poética de Artur Azevedo. É o que podemos concluir do entrecho que abre o conto "Pipi". Ali vemos a personagem voltar à carga contra o narrador, censurandolhe os contos:

ELA - [...] Sabe que eu deveria recebê-lo com um sorriso de triunfo?

EU - Por que, dona Henriqueta?

ELA - Então? Que lhe dizia eu dos seus contos do País? Veja os protestos que têm provocado! O outro dia estive com o Jovino, secretário da folha; disse-me que já não têm conta os pais de família epistolarmente indignados contra o senhor.

EU - Ainda bem que, sem o querer, contribuo para o equilíbrio das finanças do Estado, fazendo aumentar a receita do correio.

ELA - Aí vem o senhor com as suas facécias do costume! Creia que esses protestos me incomodam, porque sou sua amiga sincera.

EU - A senhor acha que esses pais de família tenham razão?

ELA - Se quer que lhe fale com franqueza...

EU - Acha?

ELA - Acho, sim; o senhor é por demais cru nos seus escritos. 
EU - Mas por amor de Deus, dona Henriqueta! Há tanta gente que os aplaude...

ELA - Deixe aplaudir. Que lhe importam aplausos inconscientes? (AZEVEDO, [1924], pp.222-3)

Em seguida, dona Henriqueta sugere ao narrador "que seja mais escrupuloso na escolha dos seus assuntos", sugerindo-lhe que escrevesse "alguns contos cujos protagonistas sejam crianças”. Está lançado o estopim para o início da narrativa "de encaixe":

ELA - As crianças prestam-se à invenção de histórias divertidíssimas. Olhe, contaramme uma que pode servi-lo - e afianço-lhe que essa é autêntica ${ }^{3}$.

EU - Ouçamos. (AZEVEDO, [1924], 225)

Mas não sem antes um último cuidado:

ELA - Nesse caso, acompanhe-me até o largo da Carioca; vou tomar o bonde.

EU - Com muito prazer.

ELA - Vamos aqui pela rua do Carmo; não quero atravessar a rua do Ouvidor em companhia do autor do Númbaro.

EU - Ah, dona Henriqueta, a senhora é implacável! (AZEVEDO, [1924], p.225)

O conto até poderia ser lido, embora o assunto fizesse corar, mas uma senhora jamais poderia ser vista ao lado de um escritor que tudo sabia contar.

\section{Considerações finais}

\section{Como bem registrou Josué Montello:}

Artur Azevedo tirou de seu próprio mundo os tipos e entrechos dos contos que ia deixando nos jornais e revistas do Rio de Janeiro e depois reunia em volume, para destino menos efêmero. Na singeleza de seu estilo, ajustou o traje adequado aos seres que veio compondo pelo tempo adiante. Não refez uma página, pelo gosto de encontrar, no ritmo da frase, a melodia nova ou esquecida. Nem se preocupou em convergir para a folha em branco os grandes dramas e as supremas desesperações. Limitou-se às pequenas cenas da comédia humana, que estavam ao alcance de seus olhos, nos horizontes que o destino lhe proporcionou. Mesmo assim, ele soube encontrar, pelas intuições do talento literário, o detalhe que faz a cena e o traço que marca para sempre o tipo. (MONTELLO, 1956, pp.49-50)

E é no tipo de dona Henriqueta que encontramos a leitora de seus contos imaginada por Artur Azevedo. Afinal,

o mundo representado na literatura - por mais simbólico que seja - nasce da experiência que o escritor tem de sua realidade histórica e social. O universo que autor e leitor compartilham, a partir da criação do primeiro e da recriação do segundo, é um universo que corresponde a uma síntese - intuitiva ou racional, simbólica ou realista - do aqui e agora da leitura, ainda que o aqui e agora do leitor não coincidam com o aqui e agora do escritor. (LAJOLO, 2001,p. 47) 
Compreender melhor o leitor de Artur Azevedo é, certamente, uma importante chave para a leitura de seus contos.

Notas

${ }^{1}$ Pela história descrita por Magalhães Júnior, parece-nos que o conto "Incruento" seria aquele publicado nos Contos fora da moda (1894) com o título de "A filha do patrão".

${ }^{2}$ Consultamos a $4^{a}$ edição dos Contos efêmeros para a redação desse artigo. É bem possível que o conto possa ter sofrido reformulações desde sua primeira escritura, publicada no jornal O País. Apenas uma pesquisa mais profunda poderá solucionar essa questão.

${ }^{3}$ Seria um mea culpa de dona Henriqueta pela acusação de plágio que sofreu Artur Azevedo no caso do conto "Os charutos"?

\section{Bibliografia}

AZEVEDO, Artur, Contos. Introdução de Carlos Alberto Iannone, São Paulo: Editora Três, 1973. , Contos efêmeros, 4. ed., Rio de Janeiro: Garnier, [1924].

, Contos fora da moda. Cotejada e anotada por Antônio Martins. 7. ed., ilustrada. Rio de Janeiro: Alhambra, 1982.

, Contos ligeiros. Coligidos e prefaciados por Raimundo Magalhães Júnior, Rio de Janeiro: Bloch, 1974.

, Histórias brejeiras. Seleção, prefácio e notas de Raimundo Magalhães Júnior, Rio de Janeiro: Edições de ouro, 1967.

,Vida alheia: contos e comédias. Introdução de Fausto Cunha. Rio de Janeiro: Brughera, [197-?].

GOTLIB, Nádia Battella, Teoria do conto. 6. ed., São Paulo: Ática, 1991.

LAJOLO, Marisa. Literatura: leitores E leitura, São Paulo: Moderna, 2001.

MAGALHÃES JÚNIOR, Raimundo, Artur Azevedo e sua época, São Paulo: Saraiva, 1953.

MIGUEL-PEREIRA, Lúcia, Prosa de ficção: de 1870 a 1920. 3. ed., Rio de Janeiro: José Olympio; Brasília: INL, 1973.

MONTELLO, Josué, Artur Azevedo e a arte do conto: conferência pronunciada na Academia Brasileira a 29 de setembro de 1955, Rio de Janeiro: Livraria São José, 1956. 


\section{NA FEIRA DE CAL EM BURGOS}

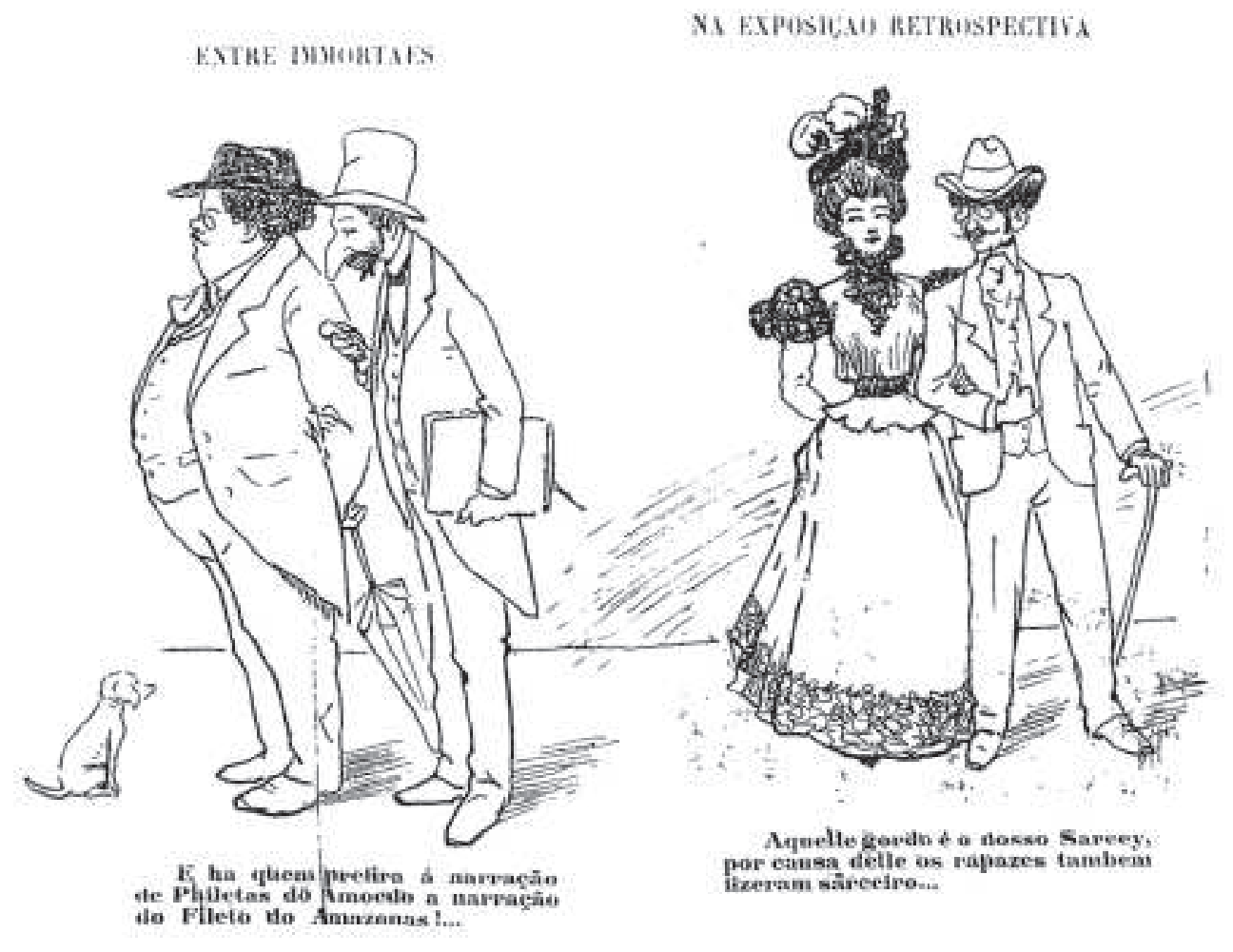

Fonte: "Mercúrio", 26/07/1898 